\title{
The Potential to Source a Patient's Imaginative Powers in Treating Cancer: Illustrated in Three Cases
}

\author{
Martin Roesch \\ Parmenides Tagesklinik, Bochum, Germany
}

\author{
Keywords \\ Psycho-oncology · Hypnosis · Meditation · Spirituality · \\ Cancer co-therapy · Mind-body medicine . \\ Patient's imaginations
}

\begin{abstract}
Background: The imaginative power of a human patient has the big advantage of sourcing his/her own depth leading to first-hand experiencing. Such experiences have a potential to make a deep impact that can be instrumental to the process of healing. Successful healing is almost inevitably linked to new recognitions and perceptions, changes in attitudes or changes in lifestyle. Therapists in charge may find that they cannot exert direct control over this process but nevertheless, there is a big inherent potential to such processes as a truly complementary approach to clinical oncology. Case Reports: Going by the characteristic of the matter, it seems impossible to conduct randomized trials; rather, we have to learn from the very individual experiences and try to find common traits. Hence, in this contribution, it is "just" three cases that are presented: patients with a pancreatic tumor, lung metastasis, and a colon carcinoma. Still, the same objectives of evaluation criteria as in any conventional clinical trial, namely overall survival and quality of life, are followed here. The presented cases are set against expected outcomes of the guideline-oriented therapy options. Conclusion: Quality of life has improved in all three cases, expected overall survival extended in one case, the second is still to be verified. Certainly beneficially, however, is the ratio of effect to - in these cases - no negative side effects.
\end{abstract}

() 2019 S. Karger AG, Basel (c) 2019 S. Karger AG, Basel

www.karger.com $/ \mathrm{cmr}$

Karger ${ }^{\prime}$ -

\section{Schlüsselwörter}

Psycho-Onkologie · Hypnose · Meditation · Spiritualität · ganzheitliche Krebstherapie · Körper-Geist-

Zusammenhang

\section{Zusammenfassung}

Hintergrund: Die innere Vorstellungskraft von uns Menschen hat den großen Vorteil, aus der Quelle unseres tiefen Selbst heraus in ein eigenes, unmittelbares Erleben zu gelangen. Eine solche Erfahrung kann für den Heilungsprozess nützlich sein. Nachhaltige erfolgreiche Heilung ist fast immer verbunden mit neuen Wahrnehmungen und Verhaltensmustern oder Veränderungen des Lebensstils. Auch wenn Therapeuten keine direkte Kontrolle über einen solchen Prozess ausüben können, so liegt dennoch ein Potential in einem solchen ergänzenden Beitrag zur klinisch-onkologischen Versorgung. Fallberichte: Aufgrund der radikal-individuellen Charakteristik dieses Themas erscheint es fast ausgeschlossen, randomisierte Studien durchführen zu können. Eher können wir von Einzelerfahrungen lernen und versuchen, gemeinsame Muster zu eruieren. Daher werden in diesem Beitrag "nur" drei Fallbeispiele vorgestellt, Patienten mit einem Pankreastumor, Lungenmetastasen und einem Kolonkarzinom. Allerdings gelten die gleichen wesentlichen Beurteilungskriterien wie auch in Studien, nämlich das Gesamtüberleben und die Lebensqualität. Die präsentierten Fälle werden verglichen mit den zu erwartenden Ergebnissen einer an Leitlinien orientierten Therapie. Schlussfolgerung: Lebensqualität ist in allen drei Fällen verbessert, das zu erwartende Gesamtüberleben in einem der Fälle über- 
troffen, im zweiten Fall ist die Verifizierung noch ausstehend. Vorteilhaft bei dieser Art von Intervention ist sicherlich das Verhältnis von Wirkung zu in diesen Fällen keinen negativen Nebenwirkungen. (c) 2019 S. Karger AG, Base

\section{Introduction}

Imaginative powers may start out with desired visualizations or other sensations. But if accompanied associations are allowed in a chain-like sequence, then these visualizations or other sensations soon refer to a realm that is beyond cognitive awareness. There may be an intuition, there may be a hunch, but mostly its content would not yet have emerged in the awakened consciousness. It lies in the realm of the unconscious mind. "It" may mean a theme, available options, guidance, the emerging of the relevant goals, a change in emotions such as angst or confidence or faith, and ultimately a pacifying power. Our unconscious mind, anyhow, is in control of a multitude of processes and functioning that is beyond our imagination. It controls hormones, neurotransmitters, organ functions, cell processes, and so much more. All our questions emerge from our waking consciousness, the answers are already available - in our unconscious mind. High time to carefully tap this potential. Occasionally, this unconscious mind raises issues that seem to have their origins long before the disease got into the picture; occasionally, themes of our ancestors come up, even odd apparent memories and images pop up; so at times, the unconscious mind seems to float in a kind of superconsciousness with no clear boundaries - reaching out. The cases below will illustrate this point without needing to adopt any theoretical concept. G.B. Schmid and J. Dispenza are two authors who give further insight in this relationship between imaginations, psychoneuroimmunology, awareness, and the power of belief systems affecting placebo and nocebo effects $[1,2]$.

\section{Push and Pull Strategy}

There are two strategies available: a push and a pull strategy. The push strategy takes a given theme where a certain outcome is desired, e.g., the intention to visualize one's NK cells, dendritic cells, or T cells is to successfully combat with cancer cells. This is the approach that pioneer O.C. Simonton favored [3] or D. Loesch followed up with concepts of imagined body psychotherapy [4]. Without doubt, this can be a very valuable approach, and selectively, it proved to achieve amazing results, though critics argue that the method fails to yield reproducible results $[5,6]$. Recently, K. Varga and others presented cases and empirical studies demonstrating the positive clin- ical outcome of applying imaginations that favor positive beliefs to healing [6-8].

In this contribution, however, we present cases initially demonstrating a very open attitude and no pre-set intention: this is the pull strategy. A mere frame is given to the patient to allow himself/herself to sink down, deep down into one's own unconscious mind, and let the flow of images just occur. There is an inner guidance of this process that has an enormous intelligence to know what a patient can bear at a given time and what would be beyond. Thus, we allow for surprising turns to occur and merely watch what associative images and symbols emerge. This is the language of the unconscious mind: it is not English, it is images and symbols clarified and amplified by feelings. S. Fruth pioneered and specialized in one aspect of this strategy: the imagined body travel [9]; the first two of the presented cases in this article illustrate this concept.

There are two important characteristics in this process: First, the patient finds himself/herself in his/her own experiencing. It is one's inner film, inner dialogue, inner process. Second, a level of depth must be reached where a patient is truly surprised by the contents of the visions. It must become clear to the patient that these imaginations may be apart from the very initial beginning and are not cognitively produced. That is the level of depth we need to achieve.

\section{Methods}

The predominant method is an initially guided meditation to become fully alert and concentrated as such journeys within are rarely possible in an ordinary waking consciousness. It seems appropriate to coin the term "clinical meditation," which is in contrast to "hypnosis." It is not about inducing suggestions, which connotes manipulation, but about supporting a patient to set his/ her mind in focus and then simply observe what comes up. In hypnosis, participants usually have a reduction in their brain wave frequency from an alpha wave pattern to a theta wave pattern. In some of our patients where we fitted an EEG deduction, we observed that patients may initially follow the same pattern. However, in the subsequent stages, we have often identified increases in the beta wave and even in the gamma wave patterns of active and alert concentrations. These findings seem to be congruent to the literature [10]; however, there is still controversial discussion $[11,12]$. In the last years, the author has not observed a single case where a patient has not had a vivid and clear memory of such sessions.

First and foremost, a trustful relation needs to be established between the patient and the therapist; this needs to be experienced, and that is why at least one session of conjoint meditation is essential for the participant to subsequently reach sufficient deeper levels that can bring about a new and surprising outcome. To begin with, a brief meditation concentrating merely on one's own breathing has proved to be beneficial.

Occasionally, a patient is asked to make a drawing of his/her tumor or life situation or a state "when all is well again" using the non-dominant hand. It is a simple and very effective technique of letting the unconscious mind express itself. One such illustration is presented in the first case discussed next.
Roesch 


\section{Cases}

All cases have altered names and slightly changed contexts; however, all given facts are valid, the sessions are tape recorded, and the patients gave their consent to report about their therapies. The description hereafter focusses on a selected single session in each of the cases to best illustrate the guidance of a patient's imaginative powers.

\section{Case A: Trude G. - An Elderly Lady with a Non-Resectable}

Pancreatic Cancer

Initial Clinical Status

At the time of initial diagnosis, the patient, Trude G., was 72 years old. She was diagnosed with pancreatic cancer (ductal adenocarcinoma), already so advanced that it was evaluated as not resectable anymore. Further, the tumor had already metastasized into the colon and the peritoneum. This made the patient a palliative case, as with the majority of newly diagnosed pancreatic tumor cases [13].

The clinical treatment was chemotherapy with Folfirinox regimen as recommended by the results of a recent trial [14]. Additionally, the patient received i.v. injections of mistletoe (viscum album) and passive hyperthermia.

Trude G.'s Personal History

Trude G. came from a large birth family. Her mother had twelve pregnancies, where six survived beyond birth. The patient was the eldest living child. Her childhood was without personal traumata; however, she was extensively involved in caregiving, looking after her younger siblings, and in the family's farm work.

She opted nursing as her career choice. Trude G. was happily married, had raised three children, and twice experienced miscarriages. She never gave up her career and was the classical housekeeper, looking after her husband and children.

\section{Interventions and Development of Awareness}

Our interventions with Trude G. began 6 months after she had been diagnosed, extending to only six sessions, one per week. During our first few intervention sessions, a primary need to pacify the inner child in her emerged (theme of being left alone; always having to be available for others). In the course of the meditations, the initial free visualizations surprisingly twice evoked the image of a cage. In a subsequent hypnotic meditation, undertaking an imaginary travel into her body, Trude G. spontaneously decided upon the uterus as the destination instead of the originally intended pancreatic region. Here, with her imaginative powers, conciliations took place with the two children she had lost in her pregnancies.

As a further step, Trude G. was asked to draw an image of her tumor situation with her non-dominant hand. She was asked not to ponder over it but start with anything that came to her mind as she picked up the pencil. The result is shown in Figure 1.

At first sight, this drawing may look like a crude image of the pancreatic organ with caput to the left and tail to the right. However, another suspicion proved right in the next session. It was a hypnotic regression into the womb before birth. To a normal person who, during meditation, has not yet gained such an experience of the so-called elliptic consciousness, it may appear odd to be able to regress to the early memories of childhood, the birth process, or even episodes during the embryonal state while simultaneously being in the now, awake and alert in observing these memories with great subjective certainty. Nevertheless, it is a reproducible fact that humans can experience this, proven by a large number of witnesses and reports about such cases [15-19].

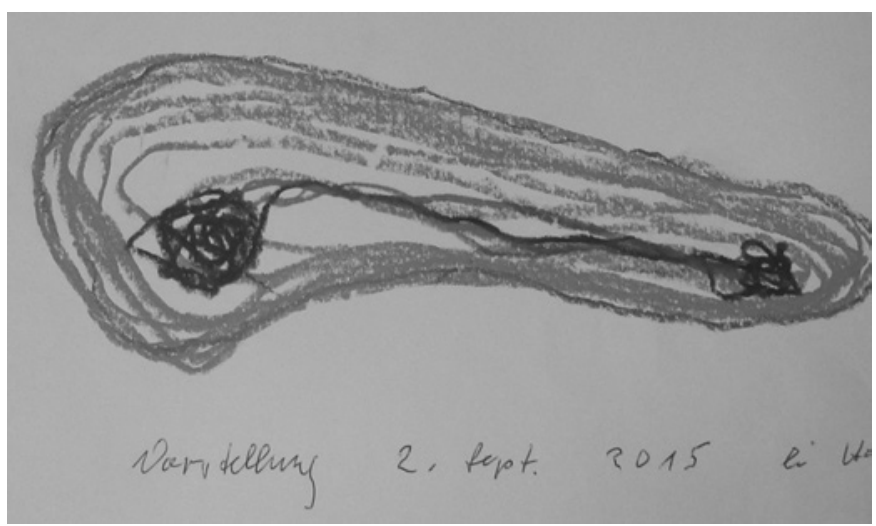

Fig. 1. Trude G.'s drawing of her tumor situation.

With Trude G., after some sensing into her embryonal body and its scope of movement, a sudden insight occurred: I am not alone here! Trude G. perceived something at the edge, something discarded, as she put it, something about to shrivel off. She sensitively traced the insight, and it turned out to be a second embryonic living being (quote: "I sense it as femaleness"), a later departure in pregnancy eventually undetected, certainly never mentioned by her mother. The subsequent process was accompanied by deep emotion and comprised clearly seeing the situation, building up of communication with the lost twin sibling and, most importantly, a mutual reconciliation in a sincere and vivid imagination. Reproduced here are her - translated - quotes: "All gets much lighter and the rays of light are directed towards my sister... almost a light appearance" and "it appears to me, she has straightened up and says: "Take notice of me."” a big relief and feeling of happiness followed and Trude G. spontaneously gave her second prename to the little twin sister and promised from now on to look with her eyes for the twin sister as well. Trude G. felt freed from a subtle feeling of guilt that she never really consciously recognized and, in the very session, understood what could have been the underlying cause for her lifelong need to always be present for others.

\section{Outcomes (Further Clinical Development)}

The actual pancreatic tumor site - unexpectedly - turned into residuum state and remained as such until her death. It did not grow any further! The tumor in the colon, however, progressed leading to an ileus, on which the patient died 15 months later. Nonresectable pancreatic cancer is one of the fiercest tumor entities with a very short life expectancy. Statistically, the mean overall survival under guideline therapy for a non-resectable pancreatic tumor is 6-11 months after initial diagnosis [14, 20-23]. Trude G. had lived up to 24 months, reaching more than double this expectancy.

\section{Concluding Discussion}

A common denominator from Trude G.'s biography is her devotional presence for others. It seems that only in permanently caring for others, a subconscious feeling of guilt was kept at bay.

\section{Why Now a Pancreatic Tumor?}

This is just a thesis of an interpretation: A main function of the pancreas is to produce insulin. Insulin is needed for all cells to be able to uptake glucoses, which in turn fuels the cells to produce energy via the citric acid cycle. It could be viewed as a self-sabotaging effect, not allowing oneself to continue prospering. It would 
reduce and ultimately hinder the cells to uptake nutrition, ensuing a gradual starving process. This happened in a time frame when the need to care for others ceased. She had retired as a nurse and her own children had grown up, left the house, and were about to set up their own families. It is interesting to note that following our clinical meditation intervention, the actual tumor in the pancreatic region has ceased to grow - though there was no regression either. May be the tumor load in total had already gained too much expansion in order to be entirely reversible; as mentioned, the patient died from an ileus effected by an already existing metastasis in the colon. But still, her 24-month survival after initial diagnosis is remarkable and against all ex ante expectations.

Case B: Dagmar F. - A Palliative Patient with Lung Metastases and Agonizing Coughing

Initial Clinical Status

Dagmar F. was a 62-year-old lady with a corpus uteri adenocarcinoma metastasized in the lung and liver. Initial diagnosis was made in 2/2014 followed by surgery, radiation, chemotherapy (interrupted due to high toxicity); in 2016, metastases were recorded in the lymph nodes, kidney, and lung, and later in the liver and colon, again addressed with radiation therapy. In 2017, a new tumor progress was found, now treated with metronomic chemotherapy conjoint to mistletoe i.v. injections, hyperthermia, and further supportive measures to her immune system. Status at the time of our interventions (late summer 2017): the main subjective complaint was dyspnea and frequent heavy coughing attacks.

Dagmar F.'s personal history revealed no obvious pattern. She had a somewhat rebellious adolescence but then worked successfully, being employed in the upper management of a mid-sized business. After her marriage and birth of her first child, she stayed home as a caretaker to her husband and the children. She mentioned only one crisis, which had eventually passed by, about 6 years before the outbreak of her cancer.

\section{Interventions and Development of Awareness}

The most tormenting experience in Dagmar F.'s health status was the severe coughing attacks that plagued her during the day and, gradually, in increasing frequency at night too. It is this theme that she addressed as her prime burden.

We agreed to conduct a hypnosis-induced meditation using the theme of an imaginary journey into her body, into her lungs. We held a few preceding meetings, with guided meditation as well, and thus, we managed to build a good, trustful relationship with her. We chose a safe location as the starting point, where Dagmar F. could visualize seeing herself in a mirror. In her imagination, she reached out, taking her now diminishing mirror picture into her palm, and let it shrink even further, growing smaller and smaller until she sank gently through her skin and found herself inside her hand safely floating in a small blood vessel. Please note that by now the patient had changed her perspective and dwelled in the outlook from the consciousness of her previously mirrored diminished self.

In the further course of the meditation, Dagmar sees herself on the way to the lungs. All of a sudden, however, a giant greyish guardian steps forth and blocks her further progress! She can communicate telepathically with him and, in her mind, can hear him explain that his task is to guard what is below. Peeping to the side of him she sees further down a "disgusting whitish goo," that does not belong there. The question is then asked: "Who gave that controlling order to this guardian?" And to her own surprise, Dagmar F. hears the response in her mind: "From me." She herself seem to have given that order.

A further intervention set the frame to inquire into this order, to "check the archives" as to what were the circumstances at the time when this task was seemingly assigned. The patient, in her imagina- tion, made a mental jump to the brain where the flow of images immediately set in again. She reports being received by a polite assistant who guided her through long corridors. She sees herself stopping by one of the doors and opening it. There are long rows of shelves and she confidently walks along to the obviously known target. "It's there." To my question "up above or down below?" Dagmar F. responds clearly, "It's here up above on eye level. It is an audio tape" (and indeed as it proved, the content was conscious and not in the lower unconscious mind). We take this tape and together in her imagination we walk to the play recorder where it can be inserted. Before pushing the play button, she reconfirms that it is an audio tape not a video tape. Indeed, seconds later, Dagmar reports she hears her own voice. She recognizes the situation. It is about 6-7 years ago. She hears herself expressing: "It's becoming all too much." The situation at the time related to her financial issues and relations in the core family. We examined this situation in detail and finally pacified the associated emotions. After this intervention, the recorded tape was overwritten: "I let lose my felt responsibility. I let lose the need to control all and everything. All runs well and is fine as it is. I respect and love myself just the very way I am."

Dagmar F. placed the tape back into the shelf and jumped back to the lungs. The grey guardian was still around; however, he was not a giant anymore but rather normal sized and he seemed irritated. He did not know what to do there anymore. As Dagmar F. suggests him, he may leave, he would be freed now from his duty, and he, in her imagination, reacts with relief and walks away. Now she could directly observe the previously seen "disgusting whitish goo." She felt that it would want to leave on its own. We made use of a spontaneous coughing episode to watch how this goo was shaken loose by the cough and how parts of it were taken away by this impulse to cough. Dagmar F. listened to the suggestion: "Each coughing now shakes loose some of this goo and can carry away bits and pieces. Each coughing now supports the goal to be able to breathe freely again."

Outcome (Further Clinical Development Related to the Coughing Attacks)

A week later, the patient reported that her coughing had decreased significantly in the last 7 days. However, it still occurred, especially in the morning. Three weeks later, coughing was no longer the theme and when questioned about it, Dagmar F. had almost forgotten about it and she reflected it with herself saying that "yes, indeed, it is gone."

The general tumor situation, however, far advanced at the time, could not be halted and continued to grow. Thus, in this case, the overall survival could probably not be influenced; the patient died 4 months later, at the end of December. At the time of this intervention, she was already highly palliative. But still, the continuous torturing coughing attacks could not only be minimized but almost completely brought to disappearance. This meant a valuable gain in quality of life, allowing treasured time and conversations in a quiet and peaceful atmosphere with her dear ones.

\section{Concluding Discussion}

Over and over again, it is amazing that in trance, we can influence bodily functions that normally are not in our conscious control. The surprising finding of Dagmar F. that it was herself who had activated the guardian was a focal recognition. In its conclusion, it meant that she herself could as well correct and change her situation - which she actually experienced in her imagination and found verified in reality. Of eminence is the fact that these processes are purely watched and observed and not actively devised in a cognitive way. This neutral perspective of observing is a crucial element in a successful trance. It induces the observed content into 
a belief with the needed intensity to create a subjective reality. This confirms a widely spread observation: perception is reality. The coughing had disappeared!

\section{Case C: Ulma X. - Rectum Cancer - A "Special” Imaginative} Intervention (Excerpt)

The next contribution again only covers one section of the process with this patient, namely a single session. This session illustrates the potential variety of different influences and situations one can encounter in the setting of a true pull strategy session, allowing the flow of a session to be led by the guidance of the patient's consciousness.

\section{Initial Clinical Status}

Ulma X. was a 48-year-old female patient with rectum carcinoma (ypT3, ypN1a, grade 3). First diagnosis was in 1/2016, treated with neoadjuvant radiation (45 Gy) and chemotherapy (5-FU, Folfox), then surgery R0 resection and further biological supportive measures; her current status at the time of intervention (3/17) as of now (06/19) is tumor free.

Main subjective complaints at the time of the intervention (March 2017) were the many difficulties in her daily life related to her intestine. Besides stomach ache and pinching sensations, the many unexpectable and sometimes often inappropriate disposals were embarrassing. About a year after her surgeries, Ulma X. was still angry with her guts. Asked about her current emotional condition, Ulma replied she continued to experience much stress and at times felt fierce anger as well as sadness. These emotions were likely be additional stressors to her intestine and outflow pattern, she concluded.

\section{Interventions and Development of Awareness}

We started with a meditation. One beneficial entry was to concentrate on breathing. The rhythmic breathing in and breathing out goes conjointly with a sensation to feel that new fresh energy flows in with each inhaled breath, and with each exhaled breath, stress and burden is released and one can sink deeper and deeper into oneself. Sooner or later, the breath flows at its own pace and depth and brings us into the desired pure observing mode.

While Ulma continued to watch her breathing, she was asked to imagine a mirror in front of herself. When she confirmed that she was in front of her imagined mirror, we asked her to merely look into this mirror. Surprisingly, what she saw was not her mirror image but a cloudy darkness. She was asked to wipe this darkness away with her hands. As she did, she saw a gestalt; her mirror image showed a young man!

He looked at her, saying nothing. Ulma is now asked whether she would agree that this gestalt may use her voice and body to be able to communicate. Ulma was very calm and interested herself and willingly agreed to the suggested process.

Immediately, in her imagination, Ulma sees herself as a healthy young man, about 25 years old. She hears herself respond to the question about name: "My name is Marcel." Quite obviously, this young Marcel is another person as the female Ulma. Asked to look down at himself, Ulma/Marcel says: "I am barefoot, have rolled up trousers, blue ones, a bright short sleeved shirt... and long hair... and yes, I am male." We test further and ask Marcel whether he is aware about the fact that he seems to be living in the body of another person. And we ask him whether he is aware that he may be dead as a human being. He hesitates in responding but agrees that he is living in the body of Ulma and is co-experiencing her emotions.

Further, we ask him whether he can show us what and how his last life had been. Ulma/Marcel at once starts reporting about a beach and seascape surroundings. The next moment, there was a note of anxiety in the voice. We reconfirm and reinforce the note and closely monitor its somatic effects. We then pose a simple question: "What is the situation now?" From the voice came a vivid stream of words: "There is a volcanic eruption... lava already flows down the hills... the whole village is in panic." Marcel sees many folks dying and running, and he too starts running. He reports seeing his family die. He runs to the sea... jumps in... but shortly afterwards, he experiences he is to drown ("I get no air anymore, I fight... I am drowning now... I die..."). He feels anger and rage that he is not allowed to live on in this beautiful life and he experiences sadness, somatically in the locations that are all too well known to Ulma (please note that initially, before the session, Ulma complained about fierce anger and sadness). His narration flows vividly now.

Marcel experiences his death, but for the first time, he now seems to be able to accept it and turns his eyes upward. He experiences himself floating upward through the clouds into the light. He spots other sparks of light. It may have been interesting to follow up on this; however, it has nothing to do with our patient anymore.

Before we finally let go on Marcel, there was a last energy exchange: Ulma sees herself standing opposite of him and commands all of her energy that eventually may still be with Marcel to return back to her and reversely letting all the energy that would be Marcel's flow back to him. In her imagination, she sees colored little balls swiftly running in the two opposite directions. Then, Ulma was ready to take up sole charge of her own body again and felt calm, relaxed, and still puzzled.

\section{Outcome (Further Clinical Development)}

A few weeks later, the patient reported on a subjectively perceived improvement to her gut's annoying life-of-its-own, but not to the extent that the problem had resolved for good. Despite the change, Ulma reflected that there were still situations when her intestine chose to set a different priority than she would have preferred. Nevertheless, her anger at the intestine had got replaced by an extended understanding and Ulma summarized for herself: "I feel now that my intestine is a mirror to me; he strikes as soon as I put up too much pressure." To Ulma, putting up pressure is an expression, as she explains, referring to her own expectations to changes that do not seem to occur rapidly enough.

Up to date, the patient is tumor free (June 2019), as it would be expected in the majority of such cases [24]. Though a quality of life questionnaire does exist for cancer patients [25], it is my observation that outside of studies or mandatory documentation requirements within certified cancer centers, the "quality of life" aspect is rarely documented, neither in a systematic manner nor long enough to be able to compare it with other patients in rectal cancer. As in Ulma's case, we have to rely on the patient's subjective evaluation. The shift of perspective that her guts are not any more the target of anger but rather an assistance to become more sensitive to her expectations and acceptance issues, is perceived by her as very valuable.

\section{Concluding Discussion}

It is essential to note that this gestalt, Marcel, appeared on its own - it was a sort of a surprise. We just went with the flow, which in turn emerged from the unconscious mind. It may feel odd to encounter outside entities, but admittedly, it is not really a rare occurrence. Usually, it has not a characteristic of an occupation, it rather appears harmless. And still, such "roommates," attracted to a certain energy with resonance to their own themes, exert a maintaining and reinforcing effect in relation to the affected emotions. In being able to release the co-influence of such "roommates," it becomes much easier to break through the emotional patterns that 
keep a person in the loop. This again is an important step for improvements to happen. This described incident certainly covers only a fragment in the path of change and healing. However, much already is achieved when a person only needs to handle one's own energy in the body.

\section{Conclusion}

There are two main criteria to evaluate the comprehensive set of therapy options in treating cancer, namely overall survival and quality of life. The minimal claim of sourcing into a patient's imaginative resources is to allow an active participation of the patient, which is satisfying in itself. It may be difficult for various reasons to prove with scientific significance that mind-body medicine contributes to the overall survival. Beyond the minimal claim mentioned above, however, there certainly is a potential to augment the quality of life and an acceptance to therapy. The potential power as drafted in the above cases is a potent and truly complementary approach and does not negatively interfere at all with clinical proceedings. The ratio of benefit to adverse side effects seems quite in favor of including mental-imaginative escorting. It would be desirable to make such offerings available to more patients than is currently the case.

\section{References}

1 Schmid GB. Selbstheilung durch Vorstellungskraft. Springer, Wien; 2010. ISBN: 9783-7091-0157-5.

2 Dispenza J. You are the Placebo. Hayhouse, UK; 2014. ISBN: 978-1-78180-257-1.

3 Simonton OC, Metthew-Simonton S, Creighton J. (1978). Getting well again. J.P. Tarcher, Los Angeles. ISBN 0-87477-070-X

4 Erstling T. Krebs mit inneren Bildern behandeln. Param Verlag, Ahlersted; 2011. ISBN: 978-3-88755-278-7.

5 American Cancer Society (1981) CA-A CANCER JOURNAL FOR CLINICIANS, June issue.

6 Kekecs Z, Varga K. Positive suggestion techniques in somatic medicine: A review of the empirical studies. Interv Med Appl Sci. 2013 Sep;5(3):101-11.

7 Varga K. Suggestive techniques connected to medical interventions. Interv Med Appl Sci. 2013 Sep;5(3):95-100.

8 Varga K, Varga Z, Fritúz G. Psychological support based on positive suggestions in the treatment of a critically ill ICU patient - A case report. Interv Med Appl Sci. 2013 Dec;5(4): 153-61.

9 Sabine Fruth is a pioneer on imagined body travel. There is a publication announced; however, oral presentations are already available: https://www.sabine-fruth.de/ikr. php

10 Jensen MP, Adachi T, Hakimian S. Brain Oscillations, Hypnosis, and Hypnotizability. Am J Clin Hypn. 2015 Jan;57(3):230-53.
11 Kihlstrom JF. Neuro-hypnotism: prospects for hypnosis and neuroscience. Cortex. 2013 Feb;49(2):365-74.

12 Ray WJ. EEG concomitants of hypnotic susceptibility. Int J Clin Exp Hypn. 1997 Jul; 45(3):301-13.

13 Siegel RL, Miller KD, Jemal A. Cancer Statistics, 2017. CA Cancer J Clin. 2017 Jan;67(1): 7-30.

14 Suker M, Beumer BR, Sadot E, et al. FOLFIRINOX for locally advanced pancreatic cancer: a systematic review and patient-level metaanalysis. Lancet Oncol. 2016 Jun;17(6):80110.

15 Association for Regression and reincarnation Research (2018); webpage chapter on Womb Regression: https://www.arrrglobal.org/wombregression.

16 Re-Living Birth and Before: Birth Trauma in the Regression Therapies (2018); Indexed Articles from the Primal Psychotherapy Page webpage: http://primal-page.com/birthart. htm.

17 Behrmann I, Sturm M. Leben und Geburt. Heidelberg: Regressionstherapeutische Dokumente. Mattes Verlag; 2008. ISBN: 978-386809-012-3.

18 Hepper PG. Fetal memory: Does it exist? What does it do? Acta Paediatr Suppl. 1996 Oct;416:16-20.

19 Cheek DB. Prenatal and perinatal imprints: Apparent prenatal consciousness as revealed by hypnosis. Pre- and Perinatal Psychology Journal. 1986;1(2):97-110.
20 Goldstein D, El-Maraghi RH, Hammel P, Heinemann V, Kunzmann V, Sastre J, et al. nab-Paclitaxel plus gemcitabine for metastatic pancreatic cancer: long-term survival from a phase III trial. J Natl Cancer Inst. 2015 Jan; 107(2):dju413.

21 Von Hoff DD, Ervin T, Arena FP, Chiorean EG, Infante J, Moore M, et al. Increased survival in pancreatic cancer with nab-paclitaxel plus gemcitabine. N Engl J Med. 2013 Oct; 369(18):1691-703.

22 Conroy T, Desseigne F, Ychou M, Bouché O, Guimbaud R, Bécouarn Y, et al.; Groupe Tumeurs Digestives of Unicancer; PRODIGE Intergroup. FOLFIRINOX versus gemcitabine for metastatic pancreatic cancer. N Engl J Med. 2011 May;364(19):1817-25.

23 Burris HA 3rd, Moore MJ, Andersen J, Green MR, Rothenberg ML, Modiano MR, et al. Improvements in survival and clinical benefit with gemcitabine as first-line therapy for patients with advanced pancreas cancer: a randomized trial. J Clin Oncol. 1997 Jun;15(6):2403-13.

24 Stewart D, Yan Y, Mutch M, Kodner I, Hunt S, Lowney J, et al. Predictors of disease-free survival in rectal cancer patients undergoing curative proctectomy. Colorectal Dis. 2008 Nov; 10(9):879-86.

25 Aaronson NK, Ahmedzai S, Bergman B, Bullinger M, Cull A, Duez NJ, et al. The European Organization for Research and Treatment of Cancer QLQ-C30: a quality-of-life instrument for use in international clinical trials in oncology. J Natl Cancer Inst. 1993 Mar;85(5):365-76. 